\title{
Efektivitas Bio-Slurry dan Mol Tapai Ubi Sebagai Bumbu Kompos terhadap Waktu Pembentukan dan Jumlah Kompos yang Dihasilkan
}

\author{
Rahayu Djawa1, Novianti Ahmad², Rahmaniar Ibrahim³ ${ }^{3}$, Sarjan Rum ${ }^{4}$, Febridhani \\ Hamid $^{5}$ \\ Jurusan Kesehatan Lingkungan, Poltekkes Kemenkes Ternate
}

\begin{abstract}
Waste management is intended to be a systematic, holistic, and continuous activity that includes reduction and handling of waste by using organic waste of household as ingredients of composting which is the result can be used as organic fertilizer. This type of research is a Experimental, with design of research is post test with group design. This research aims to determine the duration of composting and the amount of compost that produced. The design of this research is to see the effectiveness of Bio-Slurry and Mol Tapai Ubi. The amount of compost that produced for both ingredients is different. The amount of compost that produced by Mol Tapai Ubi after sieving is $31.5 \mathrm{~kg}$ and Bio-Slurry produced $30.4 \mathrm{~kg}$ compost. The most effective composting between both ingredients for the amount of compost that produced and the establishment of time that required is Mol Tapai Ubi.
\end{abstract}

Keyword : Waste, Mol Tapai Ubi, Bio-Slurry

\begin{abstract}
ABSTRAK
Pengelolaan sampah dimaksudkan adalah kegiatan yang sistematis, menyeluruh, dan berkesinambungan yang meliputi pengurangan dan penanganan sampah dengan memanfaatkan sampah organik rumah tangga sebagai bahan baku pembuatan kompos yang hasilnya dapat digunakan sebagai pupuk organik. Jenis penelitian ini adalah Experimental, dengan desain penelitian yaitu post test with control group desain. Penelitian ini bertujuan untuk mengetahui lama waktu pengomposan dan jumlah kompos yang dihasilkan. Rancangan penelitian ini untuk melihat efektivitas bumbu kompos bio-slurry dan mol tapai ubi. Jumlah kompos yang dihasilkan untuk kedua bumbu kompos berbeda. Jumlah kompos yang dihasilkan oleh bumbu kompos mol tape ubi adalah sesudah pengayakan sebanyak $31,5 \mathrm{~kg}$ dan bumbu kompos bioslurry jumlah kompos yang dihasilkan sebanyak 30,4 kg. Pengomposan yang paling efektif antara ke dua bumbu kompos untuk jumlah kompos yang dihasilkan dan lama waktu yang dibutuhkan yaitu mol tape ubi.
\end{abstract}

Kata kunci : Sampah, Mol Tape Ubi, Bio-Slurry 


\section{PENDAHULUAN}

Berdasarkan Undang-Undang Nomor

18 Tahun 2008, sampah adalah sisa kegiatan sehari-hari manusia dan atau proses alamm yang berentuk padat. Pengelolaan sampah yang dimaksudkan adalah kegiatan yang sistematis dan berkesinambungan yang meliputi pengurangan dan penanganan sampah.

Sumber sampah yang terbanyak berasal dari pemukiman dan pasar tradisional. Sampah pasar seperti pasar sayur mayur, pasar buah, atau pasar ikan, memiliki jenis yang relatif seragam. Sebanyak $95 \%$ berupa sampah organik. Sampah yang berasal dari pemukiman umumnya lebih beragam tetapi secara umum minimal $75 \%$ terdiri dari sampah organik dan sisanya anorganik ${ }^{1}$. Rata - rata jumlah sampah yang dihasilkan setiap orang di berbagai daerah dapat berbeda - beda. Sampah yang dihasilkan pada kota metropolitan, kota besar, kota sedang dan kota kecil secara keseluruhan yaitu 2,97 liter/orang/hari 2,5 liter/orang/hari, 2,28 liter/orang/hari dan 2,15 liter/orang/hari ${ }^{2}$.

Berdasarkan data badan pusat statistik menunjuakan pertambahan jumlah penduduk pada tahun 2010 Jumlah penduduk Provinsi Maluku Utara sebanyak 1.038.087 jiwa yang mencakup mereka yang bertempat tinggal di daerah perkotaan sebanyak 281241 jiwa $(27,09$ persen) dan di daerah perdesaan sebanyak 756 . 846 jiwa(72,91 persen) (BPS Kota Ternate, 2010). Alternatif pengelolaan sampah yang Jurnal Kesehatan Poltekkes Ternate baik untuk menghadapi permasalah ini Maka pengelolaan sampah dapat dilakukan secara preventive, yaitu memanfaatkan sampah salah satunya seperti usaha pengomposan ${ }^{3}$. Dengan memanfaatkan sampah organik rumah tangga sebagai bahan baku pembuatan kompos yang hasilnya dapat digunakan sebagai pupuk organik.

Kualitas kompos biasanya di identifikasi dengan kandungan unsur hara yang ada didalamnya. Kualitas kompos sangat variatif tergantung dari bahan baku atau proses pengomposan yang digunakan, sehingga perlu dilakukan penelitian agar lama waktu pengomposan dan hasil akhir pengomposan sampah organik dapat dipercepat namun berkualitas baik, khususnya kandungan unsur $\mathrm{N}$, $\mathrm{P}$, dan $\mathrm{K}$ yaitu melalui penambahan aktivator atau bahan kompos. Salah satu bahan yang dapat digunakan sebagai bumbu kompos adalah bio-slurry dan mol tapai ubi.

Jenis sampah organik yang diolah menjadi kompos dengan menggunakan campuran MOL Tape Ubi dan MOL Nanas pada hari ke-17 menghasilkan jumlah kompos yang sudah diayak sebesar $65 \%$ dari total jumlah sampah yang dibuat kompos ${ }^{4}$. Selain MOL Tape Ubi salah satu bahan yang dapat digunakan sebagai bumbu kompos adalah lumpur yang dihasilkan dari campuran kotoran dan air yang mengelami proses anaerob di reaktor. Kandungan kima bio-slurry 
adalah : N sebanyak 1,6\%, P sebanyak 1,2\%, dan $\mathrm{K}$ sebanyak $0,3 \%$, di mana hal ini dapat membantu penguraian limbah organik, dan dapat mempercepat dekomposisi bahan organik yang dapat dikomposkan, sehingga lama waktu pengomposan dapat dipercepat serta meningkatkan kualitas kompos, khususnya kandungan $\mathrm{N}, \mathrm{P}$, dan $\mathrm{K}^{5}$.

\section{METODE PENELITIAN}

Jenis penelitian ini adalah Experimental, dengan desain penelitian yaitu post test with control group desain. Penelitian ini bertujuan untuk mengetahui lama waktu pengomposan dan jumlah kompos yang dihasilkan. Rancangan penelitian ini untuk melihat efektivitas bumbu kompos bio-slurry dan mol tapai ubi.

Metode pengumpulan data dilakukan dengan melakukan observasi dan pengukuran suhu kompos. Pengumpulan data dikumpulkan berdasarkan jenis bumbu kompos dan diolah dengan cara membandingkan hasil pengukuran suhu dan kualitas fisik kompos yang dihasilkan disajikan dalam bentuk tabel dan narasi.

Jumlah sampah yang diteliti sebanyang $20 \mathrm{~kg}$ untuk masing-masing bumbu kompos dan kontrol. Dosisi yang digunakan untuk mol tape ubi dan bio-slurry (perbandingan $1: 1$ ).

\section{HASIL DAN PEMBAHASAN}

Pada tabel 1 dapat dijelaskan bahwa pengukuran suhu tertinggi pada hari pertama pada kontrol dengan suhu $45{ }^{\circ} \mathrm{C}$, mol tape ubi dengan suhu $42{ }^{\circ} \mathrm{C}$, dan Bio-slurry dengan suhu $38{ }^{\circ} \mathrm{C}$. Untuk hari terakhir pengomposan suhu dengan suhu $32{ }^{\circ} \mathrm{C}$ pada bumbu kompos mol tape ubi dan bio-slurry.

Tabel 1. Pengkuran suhu kompos

\begin{tabular}{llll}
\hline & \multicolumn{3}{c}{ Pengukuran Suhu } \\
Jenis & Pengukura & Pengukura & Pengukuran \\
\cline { 2 - 4 } Bumbu & $\mathrm{n}$ Suhu & $\mathrm{n}$ Suhu & Suhu Ke-20 \\
Kompos & Hari Ke-1 & Ke-15 \\
\hline Kontrol & $45^{\circ} \mathrm{C}$ & $37{ }^{\circ} \mathrm{C}$ & $31{ }^{\circ} \mathrm{C}$ \\
Mol Tape & $42{ }^{\circ} \mathrm{C}$ & $42{ }^{\circ} \mathrm{C}$ & $32{ }^{\circ} \mathrm{C}$ \\
Ubi & & & \\
Bio-Slurry & $38{ }^{\circ} \mathrm{C}$ & $34{ }^{\circ} \mathrm{C}$ & $32{ }^{\circ} \mathrm{C}$ \\
\hline
\end{tabular}

Sumber : Data Primer

Tabel 2. Kondisi Fisik Kompos

\begin{tabular}{lcc}
\hline Jenis Bumbu & \multicolumn{2}{c}{ Kondisi Fisik Kompos } \\
\cline { 2 - 3 } Kompos & \multicolumn{1}{c}{ Warna } & Bau \\
\hline Kontrol & Coklat tua & Tidak Berbau \\
Mol Tape & & \\
Ubi & Coklat tua & Tidak Berbau \\
Bio-slurry & Coklat kehitaman & Tidak Berbau
\end{tabular}

sumber : Data Primer dijelaskan bahwa kondisi akhir fisik kompos bumbu kompos 
kontrol dan mol tape ubi berwarna coklat tua dan bio-slurry berwarna coklat kehitaman dan untuk kondisi fisik bau ketiga bumbu kompos tidak berbau.

Tabel 3. Distribusi jumlah kompos yang dihasilkan

\begin{tabular}{|c|c|c|c|}
\hline \multicolumn{4}{|c|}{ Perbandingan Akhir Jumlah Kompos } \\
\hline $\begin{array}{l}\text { Jenis } \\
\text { Bumbu } \\
\text { Kompos }\end{array}$ & $\begin{array}{l}\text { Jumlah } \\
\text { awal } \\
\text { kompos }\end{array}$ & $\begin{array}{l}\text { Jumlah } \\
\text { kompos } \\
\text { setelah } \\
\text { penguku } \\
\text { ran }\end{array}$ & $\begin{array}{c}\text { Jumlah kompos } \\
\text { sesudah } \\
\text { pengayakan }\end{array}$ \\
\hline Kontrol & $50 \mathrm{~kg}$ & $29 \mathrm{~kg}$ & $26 \mathrm{~kg}$ \\
\hline Mol Tape & $50 \mathrm{~kg}$ & $33,3 \mathrm{~kg}$ & $31,5 \mathrm{~kg}$ \\
\hline Ubi & & & \\
\hline Bio- & $50 \mathrm{~kg}$ & $35 \mathrm{~kg}$ & $30,4 \mathrm{~kg}$ \\
\hline slurry & & & \\
\hline
\end{tabular}

Sumber : Data Primer

Pada tabel 3. dapat dijelaskan bahwa jumlah kompos yang dihasilkan sesudah pengayakan paling banyak adalah mol tape ubi dengan jumlah pengayakan yaitu $31,5 \mathrm{~kg}$.

Perbandingan jumlah kompos yang dihasilan dari dua bumbu kompos yang dipakai yaitu mol tape ubi dan bio-slurry dalam lama waktu pembentukan dan jumlah kompos yang dihasilkan, lama waktu pembentukan yang dibutuhkan oleh kedua bumbu kompos ini adalah 20 hari. Untuk kedua bumbu kompos, bumbu kompos yang paling banyak menghasilan kompos adalah mol tape ubi dapat dilihat pada Jurnal Kesehatan Poltekkes Ternate tabel 5.3 Jumlah mol tape ubi sesudah pengayakan sebanyak $31,5 \mathrm{~kg}$. Sedangkan jumlah kompos yang dihasilkan paling rendah yaitu kontrol dengan $26 \mathrm{~kg}$. Untuk bumbu kompos bioslurry jumlah kompos yang dihasilkan sebanyak $30,4 \mathrm{~kg}$.

Hasil penelitian ini sejalan dengan penelitian yang dilakukan oleh Purwiningsih, dkk (2017) yang melihat jumlah kompos yang dihasilkan di dalam lubang resapan biopori sebanyak 20 lubang dengan 5 jenis sampah dan 3 jenis MOL yang berbeda selama 20 hari. Dari hasil yang diperoleh dapat dilihat bahwa ratarata jumlah kompos yang dihasilkan untuk masing-masing MOL disimpulkan bahwa MOL yang paling cepat proses pengomposannya yaitu MOL Tape Ubi.

Suhu bagi pengomposan sendiri adalah antara $40-60^{0} \mathrm{C}$ dengan suhu maksimal $75^{\circ} \mathrm{C}^{6}$. Pematangan kompos ini ditandai dengan lapuknya tumpukan (berwarna coklat tua kehitaman). Dapat dijelaskan pada tabel 5.1 pengukuran suhu tertinggi pada hari pertama pada kontrol dengan suhu $45{ }^{\circ} \mathrm{C}$, mol tape ubi dengan suhu $42{ }^{\circ} \mathrm{C}$, dan Bio-slurry dengan suhu $38{ }^{\circ} \mathrm{C}$. Untuk hari terakhir pengomposan suhu dengan suhu $32{ }^{\circ} \mathrm{C}$ pada bumbu kompos mol tape ubi dan bio-slurry. Suhu yang diperoleh dalam proses pengomposan pada penelitian ini berada di bawah suhu optimal sehingga panas yang dihasilkan belum maksimal karena suhu 
yang didapat antara suhu $32-45{ }^{\circ} \mathrm{C}$.

Bentuk dan warna merupakan salah satu kriteria kematangan kompos. Ciri-ciri kompos yang sudah matang yaitu bentuknya hancur dan warnanya cokelat tua hingga hitam menyerupai $\operatorname{tanah}^{7}$. Warna yang dihasilkan oleh kedua bumbu kompos mol tape ubi dan bio-slurry, mol tape ubi memiliki warna kecoklatan dan bio-slurry memiliki warna kehitaman.

\section{KESIMPULAN}

Jumlah kompos yang dihasilkan untuk kedua bumbu kompos berbeda. Jumlah kompos yang dihasilkan oleh bumbu kompos mol tape ubi adalah sesudah pengayakan sebanyak $31,5 \mathrm{~kg}$ dan bumbu kompos bio-slurry jumlah kompos yang dihasilkan sebanyak 30,4 kg. Lama waktu yang di butuhkan untuk kedua bumbu kompos yaitu 20 hari. Pengomposan yang paling efektif antara ke dua bumbu kompos untuk jumlah kompos yang dihasilkan dan lama waktu yang dibutuhkan yaitu mol tape ubi.

\section{SARAN}

Berdasarkan kesimpulan di atas dapat disarankan untuk penelitian selanjutnya penggunaan bumbu kompos sebaiknya digunakan berbagai perbandingan jumlah komposi untuk jenis bumbu kompos yang digunakan.

\section{DAFTAR PUSTAKA}

1. Sudrajat, 2002, Mengelola Sampah Kota, Solusi Mengatasi Maslah Sampah Kota Dengan Manajemen Terpadu Dan Mengolahnya Menjadi Energi Listrik Dan Kompos, Penebar Swadaya, Depok.

2. Hadisuwito, Sukamto. 2012. Membuat Pupuk Organik Cair. Jakarta : Agromedia Pustaka.

3. Damanhuri, E. (1988). Optimasi Lahan Sanitary Landfill, Suatu Konsep.

Jurnal Tehnik Penyehatan Edisi Mei .

4. Purwiningsih, Dwi Wahyu dkk, Kemampuan MOL (Mikroorganisme Lokal) Pada Proses Pengomposan di Dalam Lubang Resapan Biopori. 2017

5. Anonim, 2014. Pedoman penggunaan dan pengawasan, pengolahan dan pemanfaatan Bio-Slurry, BIRU. Jakarta

6. Simamora, S. S. 2006. Meningkatkan kualitas kompos. PT Agromedia Pustaka, Jakarta

7. Kaleka, N. 2010. Kompos dari sampah 